Short Communication

\section{Management of facial wounds with missing soft tissue with local flaps}

\section{Vasilios Bousdras*}

Department Oral \& Maxillofacial Surgery, Aristotle University Thessaloniki, Thessaloniki 54124, Greece

Avulsive injuries to the face can be challenging. Soft tissue defects secondary to trauma and bites nessecitate local tissue transfer and the tissue closely resembles the missing skin in color and texture. These flaps can be rotated, advanced or transposed into a tissue defect and include:

The forehead flap (median, paramedian) for large nasal defects.

The nasolabial flap for oral defects and also defects involving the lower third of the nose.

The lid-switch flap (abbe flap) is used to reconstruct as much of the upper third of the lip.

The eyelid flap.

A patient with missing tissue from a dog bite was treated at University OMFS clinic, Thessaloniki. The patient was taken to the operating room and the wound was irrigated and debrided. The wound was clinically non-infected and the nasolabial rotational flap was outlined (Figure 1). Jagged tissue margins were excised cleanly and the flap was elevated and aesthetic subunit principles were followed (Figure 2). The defect was treated and upper lip anatomy restored (Figure 3) [1].

There was no infection or flap necrosis postoperatively and follow up visits. Treatment options of complex injuries of the face with missing tissue include early primary closure,

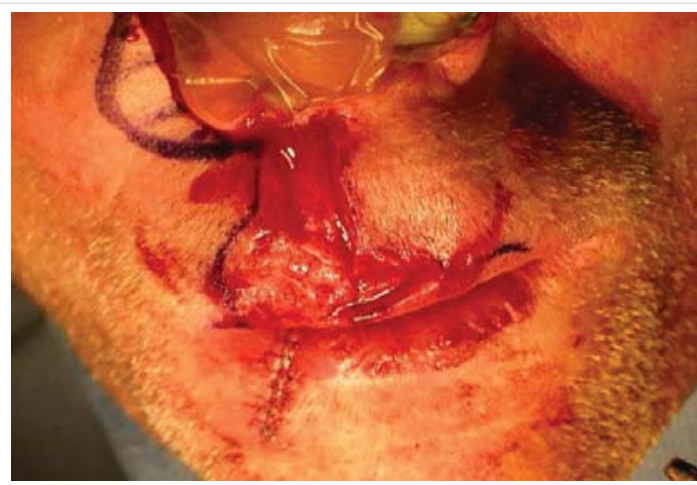

Figure 1: Significant tissue loss of upper lip after a dog bite and the nasolabial rotational flap is outlined.
More Information

*Address for Correspondence: Vasilios Bousdras, Department Oral \& Maxillofacial Surgery, Aristotle University Thessaloniki, Thessaloniki, 54124, Greece, Email:vbousdras@yahoo.com

Submitted: 31 July 2019

Approved: 31 August 2020

Published: 01 September 2020

How to cite this article: Bousdras V. Management of facial wounds with missing soft tissue with local flaps. Arch Case Rep. 2020; 4 : 048-049.

DOI: 10.29328/journal.acr.1001041

Copyright: @ 2020 Bousdras V. This is an open access article distributed under the Creative Commons Attribution License, which permits unrestricted use, distribution, and reproduction in any medium, provided the original work is properly cited.

\section{(W) Check for updates}

(1) OPEN ACCESS

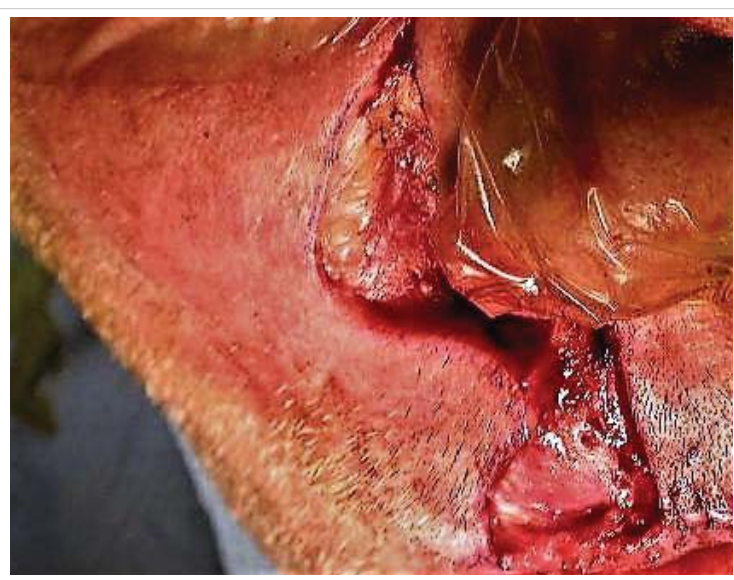

Figure 2: Wound debridement and the flap was elevated.

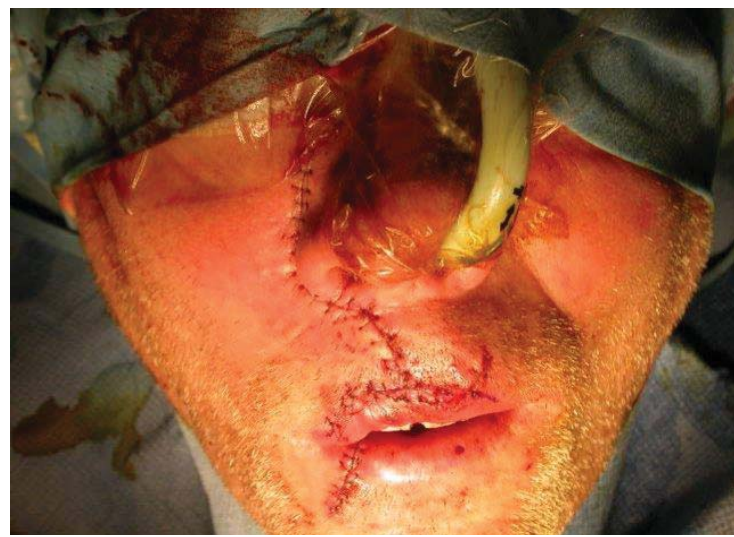

Figure 3: Aesthetic subunits and upper lip anatomy restored. 
delayed primary closure or secondary healing. Controversy still exists regarding which wounds should be treated in delayed fashion i.e gunshot wounds and extensive bite injuries. In this patient a delayed approach within 48hours was chosen with a rotational nasolabial skin flap.

\section{References}

1. Lazaridis N, Zouloumis L, Venetis G, Karakasis D. The inferiorly and superiorly based nasolabial flap for reconstruction of moderatesized oronasal defects. J Oral Maxillofac Surg. 1998; 56:1255-1259. PubMed: https://pubmed.ncbi.nlm.nih.gov/9820212/ 